\title{
The Behavior and Perception of Personal Digital Archiving of Chinese University Students
}

\author{
Feng Xiangjun \\ Department of Information Resources Management, Business School, Nankai University, China
}

Copyright $\mathrm{C} 2018$ by authors, all rights reserved. Authors agree that this article remains permanently open access under the terms of the Creative Commons Attribution License 4.0 International License

\begin{abstract}
It is widely received that personal records are a kind of unique documentary evidence for both individual and the society. Thus, same care is required for the preservation of personal records as for public records. While personal archiving in the analogue environment has been extensively studied by scholars from different fields, the rapidly changing web environment are raising new challenges on personal information behavior, further, personal digital archiving. To effectively address these challenges, it is important to first understand what the individuals' perception and behavior of personal digital archiving are. The proposed presentation aims to contribute to this knowledge by discussing the preliminary results of a mixed-method study on the behavior and perception of personal digital archiving of Chinese university students. More specifically, the mixed-method study is approached sequentially by first using a web-based questionnaire to investigate Chinese university students' perception of personal digital archiving when using email and blogs, which is followed by a semi-structured interview of information professionals to solicit their opinions on the results of the web-based questionnaire and the role of information professionals for facilitating personal digital archiving. The results of this study will shed light on Chinese university students' awareness of personal records preservation, the measures used for personal records preservation, the difficulties encountered, and responsibilities of different stakeholders (e.g., individual, web service provider, and information professionals) for personal digital archiving. This knowledge will help identify focal areas for future personal digital archiving research.
\end{abstract}

Keywords Personal Digital Archiving, Stakeholders and Responsibilities, Archiving Behavior and Perception, Chinese University Students

\section{Introduction}

As the widespread usage of the internet and digital products (e.g. computers, smartphones), the proportion of net citizens in China is growing larger and larger. The latest report published by CNNIC (China Internet Network Information Center) shows that the internet penetration in China is more than $50 \%$ and the number of net citizens is nearly 700 million. In addition, the ratio of net citizens utilizing web searching, video, social media, communication and shopping has been rising year by year. 1 A great deal of personal digital information, e.g. text, photos, audio, communication logs, has been produced, which tends to be the memories of the public, and some of which even involves users' sensitive issues, e.g. their privacy and copyright. So how to preserve and manage the large number of personal digital information efficiently has become a hot spot in current academic community.

The university students are the heaviest users of the internet and digital products, whose personal digital information is also large and various. Thus, a lot of questions relating to personal digital archiving, e.g. how the university students storing the digital information they generated, what the behavioral characteristics should be when they preserve their digital information, how they treating the activity of personal digital archiving, are urgent to be studied.

In this study, the behavior and perception of personal digital archiving of Chinese university students when they preserve E-mail and Q-zone (i.e., a social networking website created by Tencent) records would be discovered. The responsibility subjects of personal digital archiving of Chinese university students, and their specific responsibilities would be concluded. In detail, the research questions of this study include:

(1) What are Chinese university students' perception of and behavior in archiving email and Q-zone records?
1 China Internet Network Information Center. Statistical Report of Chinese Internet Development. 2016-01-22, http://www.cnnic.net.cn/hlw fzyj/hlwxzbg/201601/P020160122469130059846.pdf, 2017-03-22. 
(2) What are the problems in Chinese university students' email and Q-zone records archiving?

(3) In university students' email and Q-zone records preservation, who should be responsible for providing necessary guidance and suggestion? What are the relationships among these parties? What responsibilities does each party have?

The remainder of this article is organized as follows: first, a brief review of existing studies is presented; next, the methods used for data collection and data analysis are introduced; then, the research results and a discussion of their implications are presented; and, finally, the main findings of this study are summarized and possible areas for future research identified. It is worth mentioning that in this study, the term "archiving" was used broadest context to refer to any activities to save (or not delete) contents stored in personal email and Q-zone.

\section{Literature Review}

In brief, personal digital information refers to the personal information stored in digital form. Jones (2005) explained the connotation of personal information from the perspective of preservation ownership and divided it into three kinds. The first kind of personal information belongs to individuals, and is used by themselves. The second kind belongs to other people, which keeps close relationship with individual, e.g. one's health information controlled by hospitals. The third kind is one's experience, which neither belongs to nor saved by oneself, e.g. the information on the websites which was visited. In this study, the personal information refers to the first kind, and we emphasize the controllability of the information which was generated in the process of individual activities by general public. And then, personal digital information can be defined as the information generated in social activities, related to creators, the rights of preservation belonging to individuals, stored in digital form, and utilized for creators.

Personal digital archiving refers to a series of activities of preserving personal digital information with the help of any kind of method or tool, which emphasizes on the subjectivity of personal preservation. As a research hotspot, personal digital archiving has been attached importance to by many domestic and foreign scholars.

Cushing (2010), a researcher from the archival field, compared discussions about personal digital archiving in the archival literature to those in PIM. She analyzed archival literature in relation to the attributes for the challenges and tasks associated with personal archiving that were identified by PIM researchers (Marshall, 2008a, 2008b; Marshall, Bly, \& Brun-Cottan, 2006) and found that archival researchers had concerns about personal records in institutional archives similar to those that Marshall et al. had identified. Cushing argued that archival literature offers a corpus of academic and practical insights for personal digital archiving, especially for the challenges of curatorial efforts and value determination.

E-mail has become a popular communication method. Some scholars have recommended archiving e-mail messages (Dando-Collins, 2006; Perry,2008). Email message is a kind of digital information. So preserving personal e-mail is a kind of personal digital archiving, which relies on the awareness of their creators and the decisions they make. Some email software, such as Microsoft Outlook, supports basic archiving functionality. However, many email applications carry limitations for backup purposes (Gross, 2004), and sometimes Internet Service Providers (ISPs) go out of business or discontinuing services. Then who would in charge of archiving personal digital information. In Donghee Sinn (2011)'s paper, he examined how the general public used commercially provided e-mail services to keep their personal documents and history supports exploration into how information professionals could assist the general public in archiving their data, with a view to preservation for future generations and historians.

College students are the subjects of numerous studies of information behavior. In 2002, the Pew Internet and American Life Project released a major report on the use of the Internet by college students and how they have incorporated it into their education and social lifestyles (Jones, 2002). The report covers use of Internet features such as e-mail, instant messaging (IM), recreational online browsing, and downloadable music files. It found that as a group, college students are early adopters of the Internet incorporating new uses of its features before other population groups.

In this study, the behavior and perception of personal digital archiving of Chinese university students would be examined.

\section{Research Design and Methods}

We performed two studies and the data collection methods included questionnaire survey and interview.

Sinn et al. (2011)'s questionnaire was used, with slight adaption (Firstly, email and Q-zone are selected as the network platforms in our questionnaire. Secondly, university students are designated as the respondents, including undergraduate students, postgraduate students and doctoral candidates.), to collect data on Chinese university students' understanding of and behavior in email and Q-zone records archiving and analyzed quantitatively.

In order to improve the questionnaire draft, the suggestions and proposals from information professionals2 were adopted. After pilot survey in a small scale, final

2 Information professionals include librarians, archivists, information science students and faculty, and people who work in information-providing institutions. In our study, the information professionals we interviewed are information science students and faculty. 
questionnaire was formed. And then, we conducted the formal large-scale investigation on-line and off-line during the summer in 2016. Two hundred and seventy-five questionnaires were issued, while 273 were taken back.
In all 273 respondents, there are 100 males and 173 females; 236 undergraduate students, 30 postgraduate students and 7 doctoral candidates. Their discipline background shows as figure 1 .

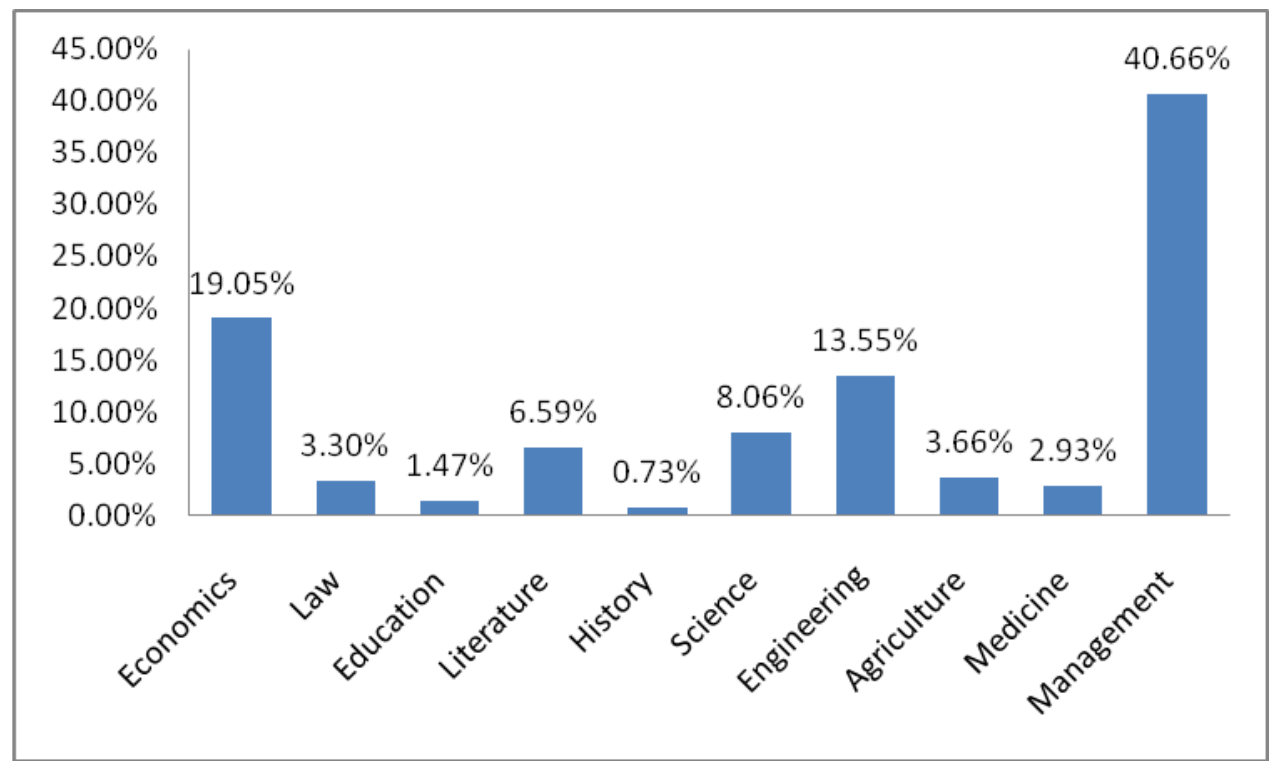

Figure 1. Discipline background of the respondents

Information professionals (IP1 IP7) were interviewed to solicit their opinions on which parties should be responsible for university students' personal web records archiving and what their responsibilities are, while the data collected was analyzed qualitatively from two dimensions: the stakeholders of personal digital archiving and their individual responsibilities.

Our interview outline includes four aspects: (1) research content, the purpose of our interview and the privacy statement; (2) problems of personal digital archiving in university students; (3) reasons why above problems existing, who should solve the problems, and how to solve; (4) responsibility, support and assistance provided by information professionals.

\section{Results}

We find, through investigation, that E-mail and Q-zone are used widely and frequently by university students.

About $96.7 \%$ university students investigated have their own E-mail accounts, while $77 \%$ have two or more, and $6.96 \%$ five or more. Among them, about $60 \%$ use E-mail one to five years, about $30 \%$ five to ten years, some even ten years or more. Nearly $47.92 \%$ university students $\log$ in E-mail every day, and $36.98 \% \log$ in once a week.

Most (88.64\%) university students have their own Q-zone accounts, while $64.1 \%$ have two or more, and $8.79 \%$ five or more. Among them, about $60 \%$ use Q-zone one to five years, about $30 \%$ five to ten years, a small part even ten years or more, which is the same as university students continuous usage E-mail accounts. As for the frequency of logging, $63.64 \%$ university students $\log$ in Q-zone every day, $22.73 \%$ once a week.

\subsection{Purposes University Students Using E-mail and Q-zone}

The purposes of university students' using E-mail are relatively centralizing (see fig. 2), the top three of which are (multi choices): (1) handling school-related things (e.g. submitting homework, uploading presentations, downloading PPT, and etc.), $75.82 \%$; (2) handling work or business related things (e.g. taking part-time jobs, club activities, and etc.), $65.20 \%$; (3) registering websites, 56.04\%. In addition, communicating with friends and families, subscribing and maintaining the information generated online are also the important purposes, whose proportions are respectively $26.01 \%$, $23.08 \%$ and $17.95 \%$. It indicates that most university students would love to regard E-mail as formal communication tool, which is used to keep track of their professional and business life.

The purposes of university students' using Q-zone are different, which are (multi choices): (1) communicating with 
friends and families $(64.10 \%)$, sharing personal interests $(61.90 \%)$, sharing professional interests and knowledge (46.52\%); (2) writing diaries (41.03\%), showing and demonstrating personal works or artifact (37.00\%), and etc. (see fig. 3). It indicates that university students tend to entertain life-related and diversified things with Q-zone, other than school-related or business-related things which are handled formally through E-mail, with the impact of social networking services (SNS). Consequently, most of them $(60 \%)$ would love to find their personal history information from Q-zones, other than E-mail (30\%), when they want to write their autobiographies, essays and update their resumes. This result is different from Donghee Sinn et al.'s (2011), which proposed as email and blog users, general public sharing similarities in the purposes of their use.

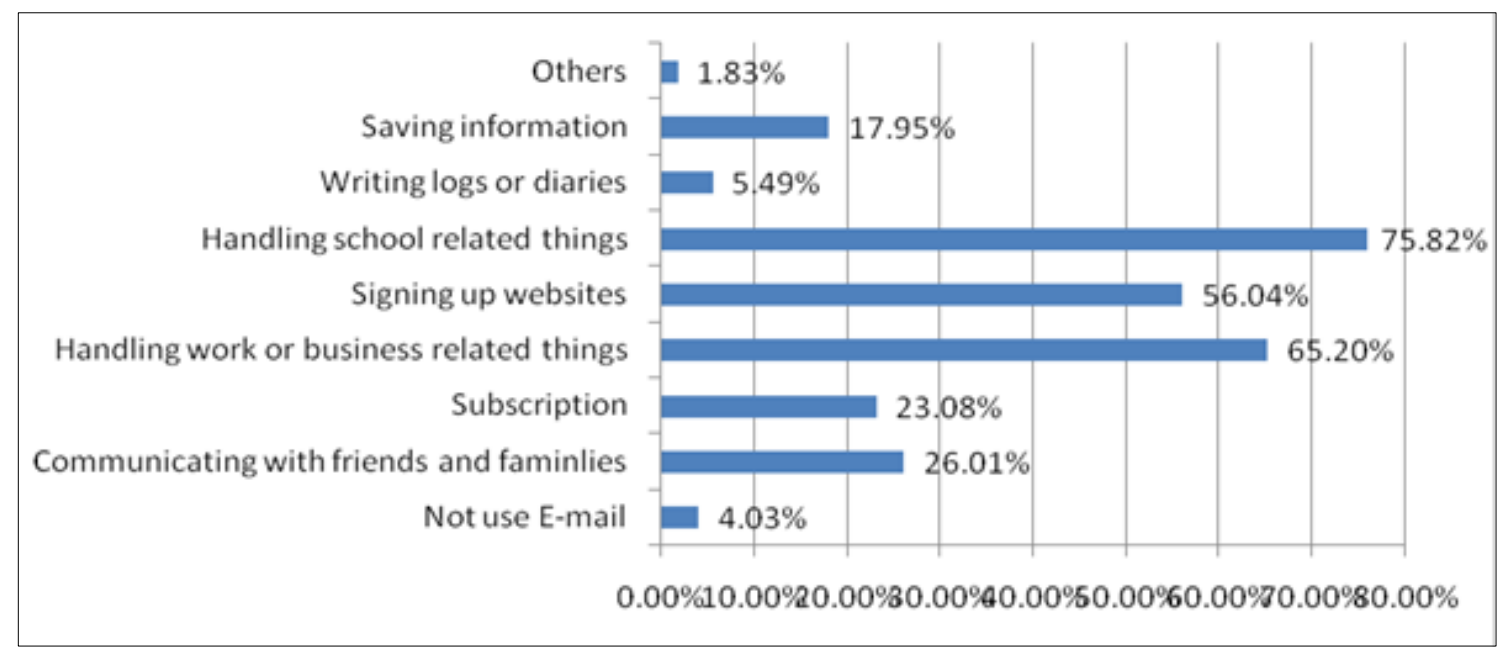

Figure 2. Purposes University Students Using E-mail

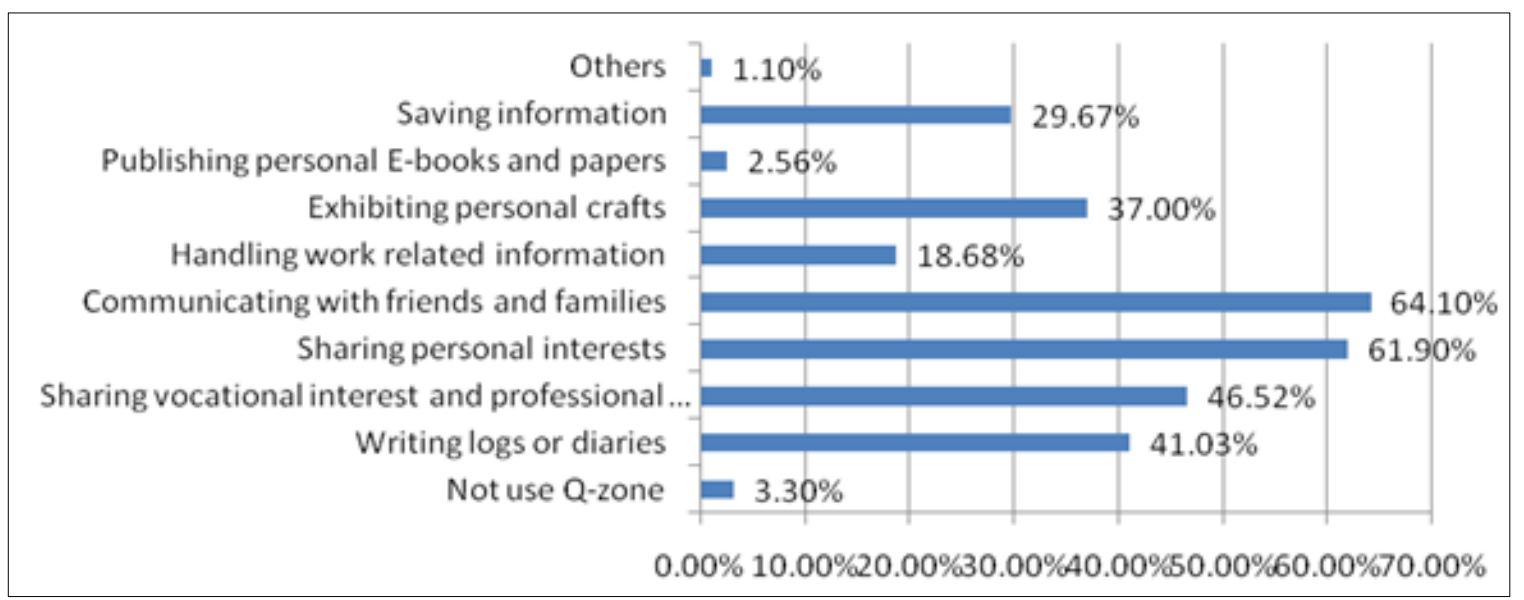

Figure 3. Purposes University Students Using Q-zone 


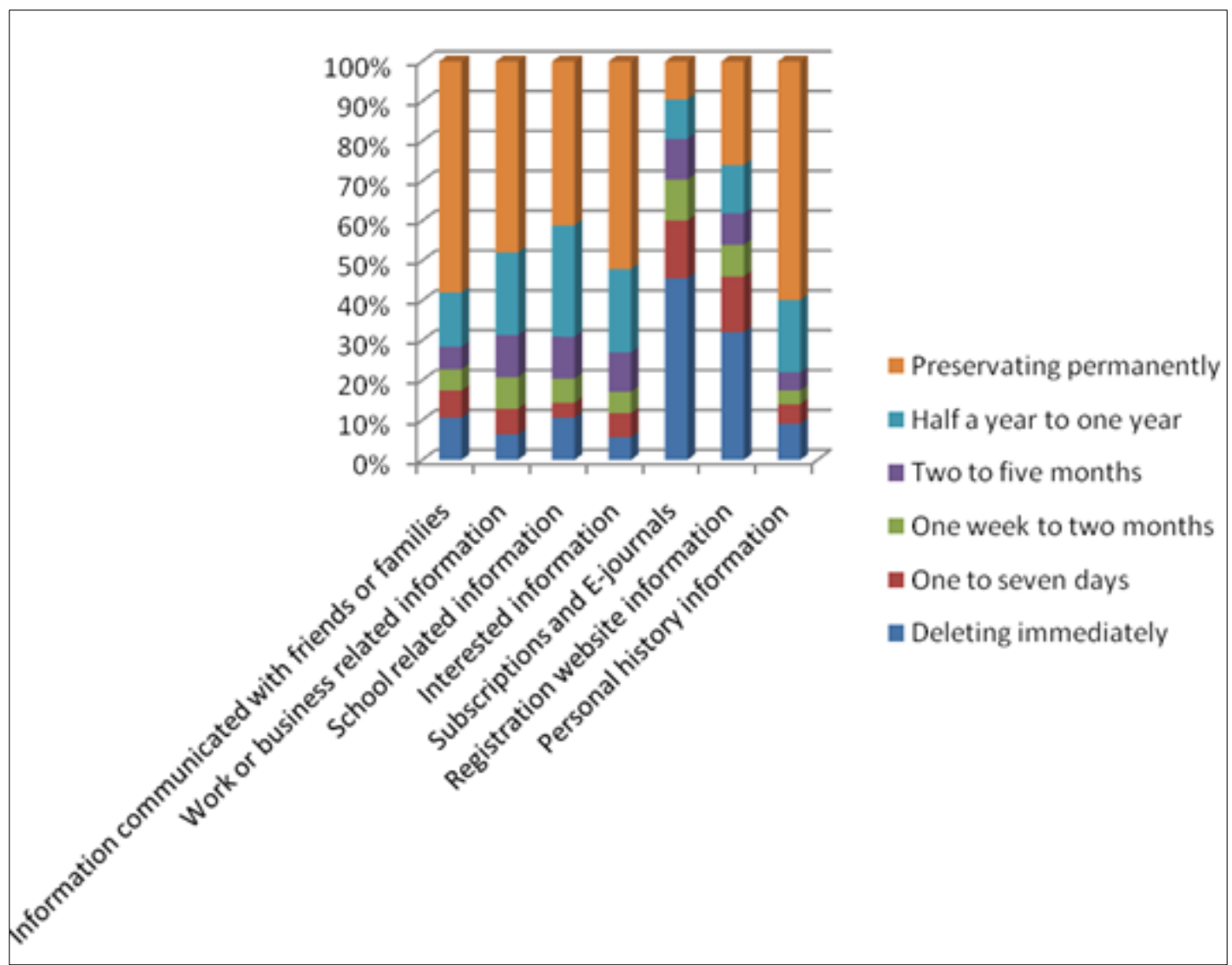

Figure 4. Length of preservation period for E-mail messages

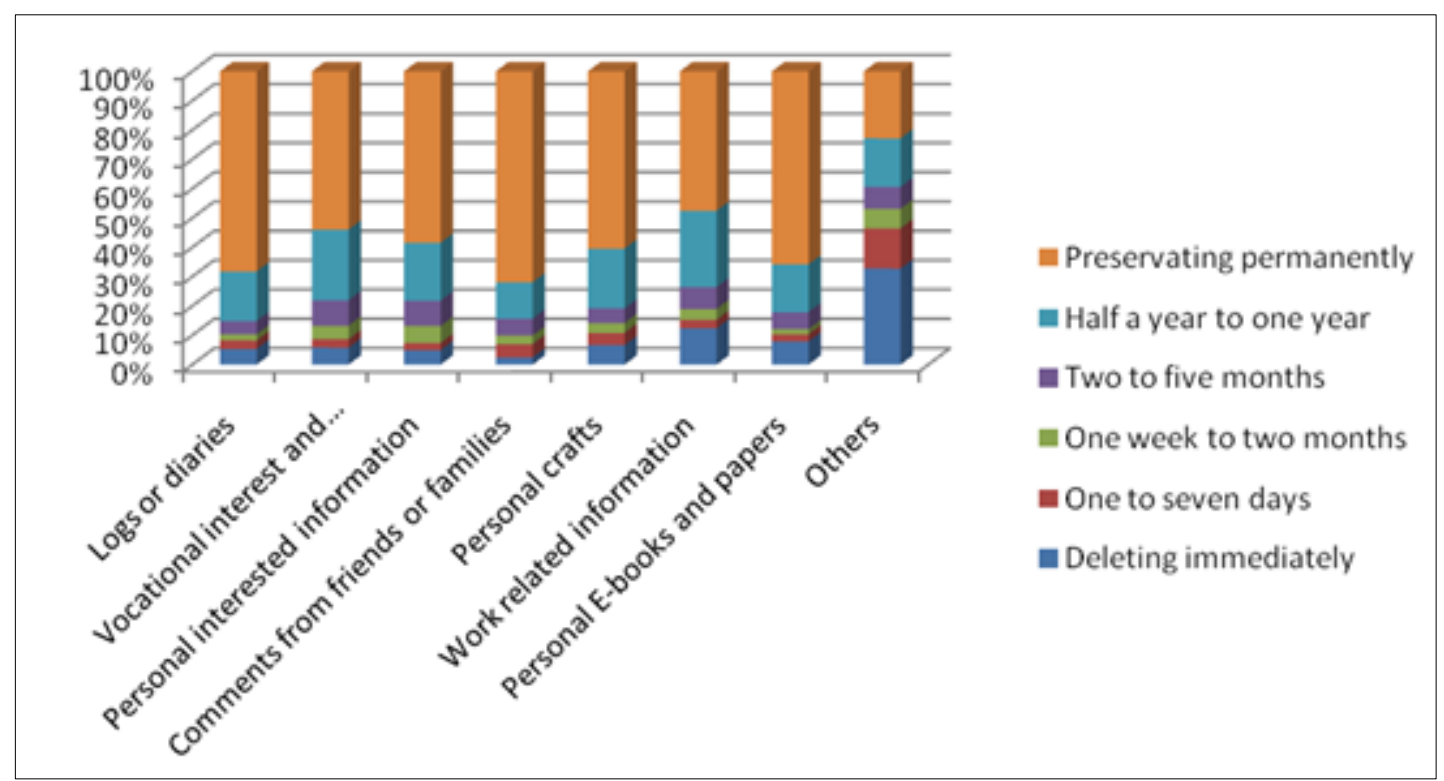

Figure 5. Length of preservation period for Q-zone messages

\subsection{Perceptions and Attitudes on Personal Digital Archiving of University Students}

It is very clear and consistent for university students towards whether deleting or preserving personal information in E-mail or Q-zone. Most university students believe each kind of information should have the value to be preserved, including subscription information, e-magzines, registering information, and etc.. (fig. 4 and fig. 5) However, the length of time of preservation is different according to different kind of information. From the perspective of university students, the information related to personal life deserves to preserve permanently most, such as personal history, information communicating 
with friends or families, personal interested information, comments from families or friends, and etc., which are also the information they refind most (e.g. $65.57 \%$ would like to refind the past they interested, $57.88 \%$ would like to refind the contact information of their old friends). This kind of information could satisfy the need of personal recalling of the past, which is a kind of spiritual demands bringing individuals joyful mood and power to work and study. Then the information related to work, business and school is also deserved to preserve to fulfill certain real tasks (e.g. completing current work or writing duties). Most university students would love to store subscription, e-magzines, registering websites, news, recommendation information for no more than one year.

The university students pay the most importance to personal information in E-mail and Q-zone from the preservation length and purposes, which derives from their mental and spiritual sustenance. In the eyes of university students, E-mail is always regarded as the most important information preservation place, although it has not been perceived as the main informal communication tool in the areas of personal life and entertainment. The personal information from E-mail is as important as from Q-zone, which deserves to conserve well as spiritual sustenance. However, the specific preservation period is decided by the degree of correlation between the information and personal history.

From another point of view, university students would feel unhappy once some kind of information is lost. Furthermore, the degree of unhappy is in direct proportion to information preservation period the university students identifies (fig. 6 and fig. 7). That is to say, the longer the information university students want to preserve, the information more related to personal history, the unhappier university students feel when it lost, vice versa. For example, when files and pictures related to one's friends or families, work-, business-, or school-related information, the information communicating with friends or families, individual interested content, professional hobbies or knowledge, diaries were lost, most of university students (approximate to 90\%) would feel unhappy. While when subscription or e-magzines, news or recommendation information were lost, most of them would not mind or feel bad.

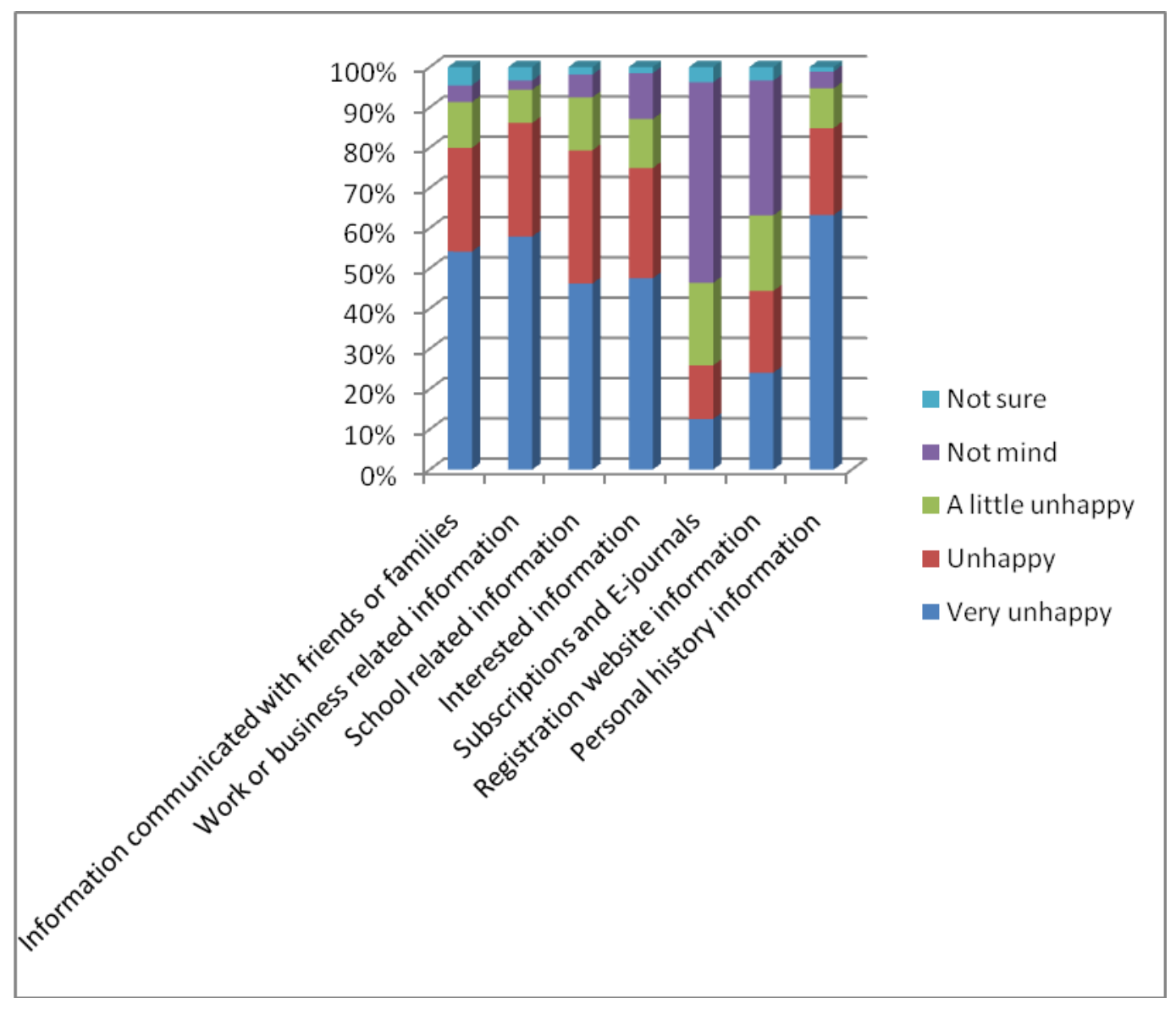

Figure 6. Feeling for lost E-mail messages 


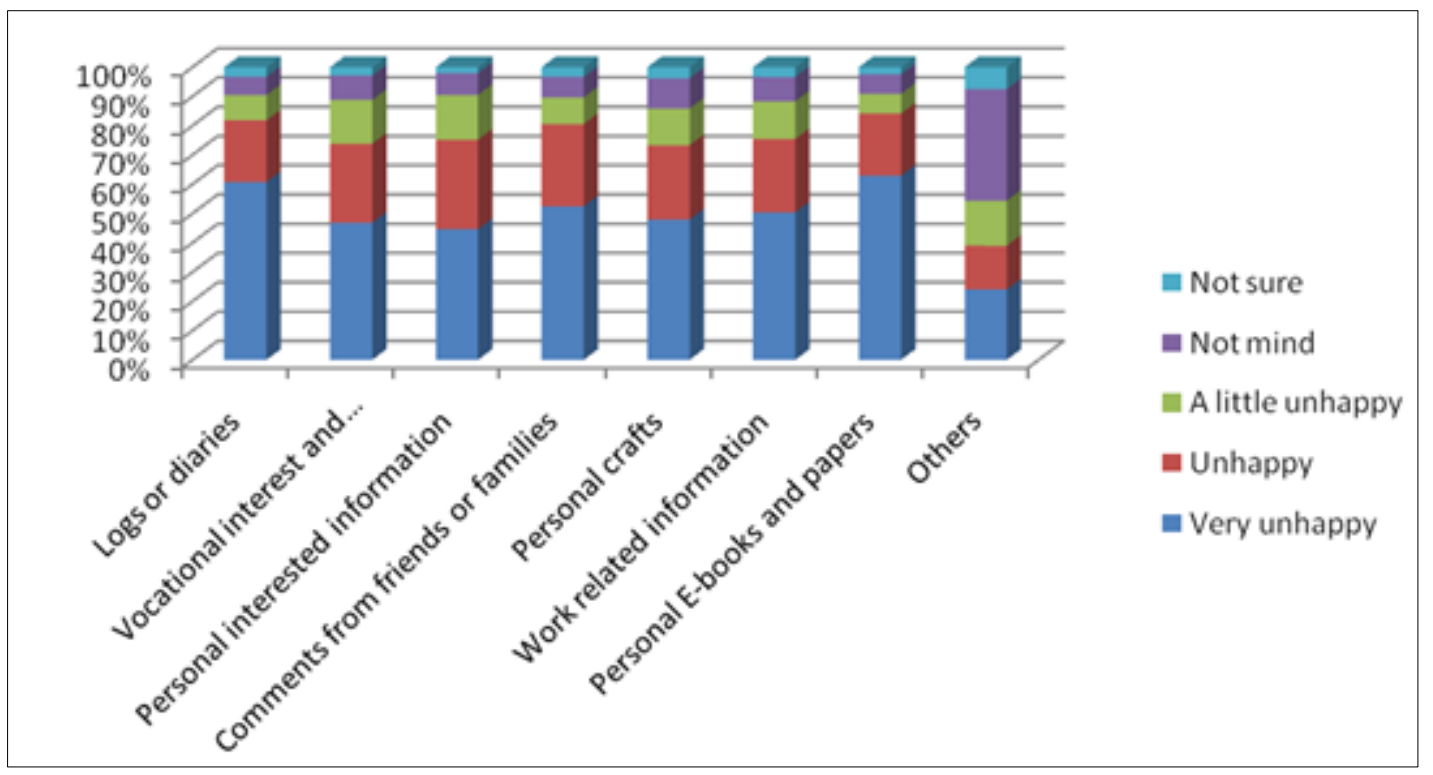

Figure 7. Feeling for lost Q-zone messages

Attitude toward Behavior (AB) is the opinion an individual performing something. The $\mathrm{AB}$ of university students' personal digital archiving including instrumental attitudes (useful or harmful, valuable or unvaluable) and emotional attitudes (pleasant or painful, like or dislike) (Bagozzi, 2001).

All in all, the attitudes of university students towards personal digital archiving are positive. From instrumental attitudes, university students all believe E-mail and Q-zone information is useful, valuable, and should be preserved, but not be deleted immediately. University students have regarded E-mail and Q-zone as the important places to preserve personal history, and the responsibility of preservation should be taken by Internet Server Provider (ISP). From emotional attitudes, university students would feel very unhappy once the information they want to conserve longer lost. Furthermore, the degree of unhappy decreases progressively as preservation period shortens, which coincides with Donghee Sinn et al. (2011)'s conclusion.

\subsection{Risk Awareness and Behavior of University Students}

Do university students have risk awareness or take actions to avoid personal information lost since they feel unhappy when the information in E-mail or Q-zone lost?

It is risky of preserving E-mail and Q-zone merely depending on ISP. For example, the information preserved on the internet would lose partly or completely if the company's policies changed, the storage space reduced, the service period shortened, or the corporation closed down, etc.. Within the investigated university students, $42.86 \%$ affirmed that they considered the possible risk of information lost because of above reasons; $43.59 \%$ did not care at all; the remainder could not be sure.

The results of the investigation mingled hope and fear, which indicate the university students have not paid enough attention to the risk of preserving personal information in E-mail or Q-zone. Although 71\% of them affirmed that they had lost their information partly or completely, and most felt very unhappy for the instability of the internet, the terrible experiences and feelings have not aroused risk awareness of preserving personal information widespread.

Furthermore, as for the solutions, the investigated university students have not persisted to back up for a long time or formed good habit, although nearly one third of them had doubted the network platforms' backup functions when they chose to register, and $42.86 \%$ did try to backup E-mail and Q-zone ever before. Within 117 university students who ever tried to back up their personal information, $40.17 \%$ of which seldom backup now, even the frequency of "backing up once a year" cannot be reached; $13.67 \%$ of which do not backup at all (see fig.8). Only less than half of the investigated university students (46.16\%) would love to backup nowadays. However the frequency is different: $10.26 \%$ backup once a year; $16.24 \%$ once a month; $11.97 \%$ once a week; $7.69 \%$ once a day. As for the question "what methods university students used to backup personal information in E-mail or Q-zone", 64.1\% chose "backing up in local computer, e.g. internal hard disk"; $38.46 \%$ chose "backing up on other media, e.g. CD, DVD, floppy disk or USB flash disk". Some of the university students who have more than one E-mail or Q-zone accounts also chose "backing up personal information in other Q-zone or E-mail accounts". 


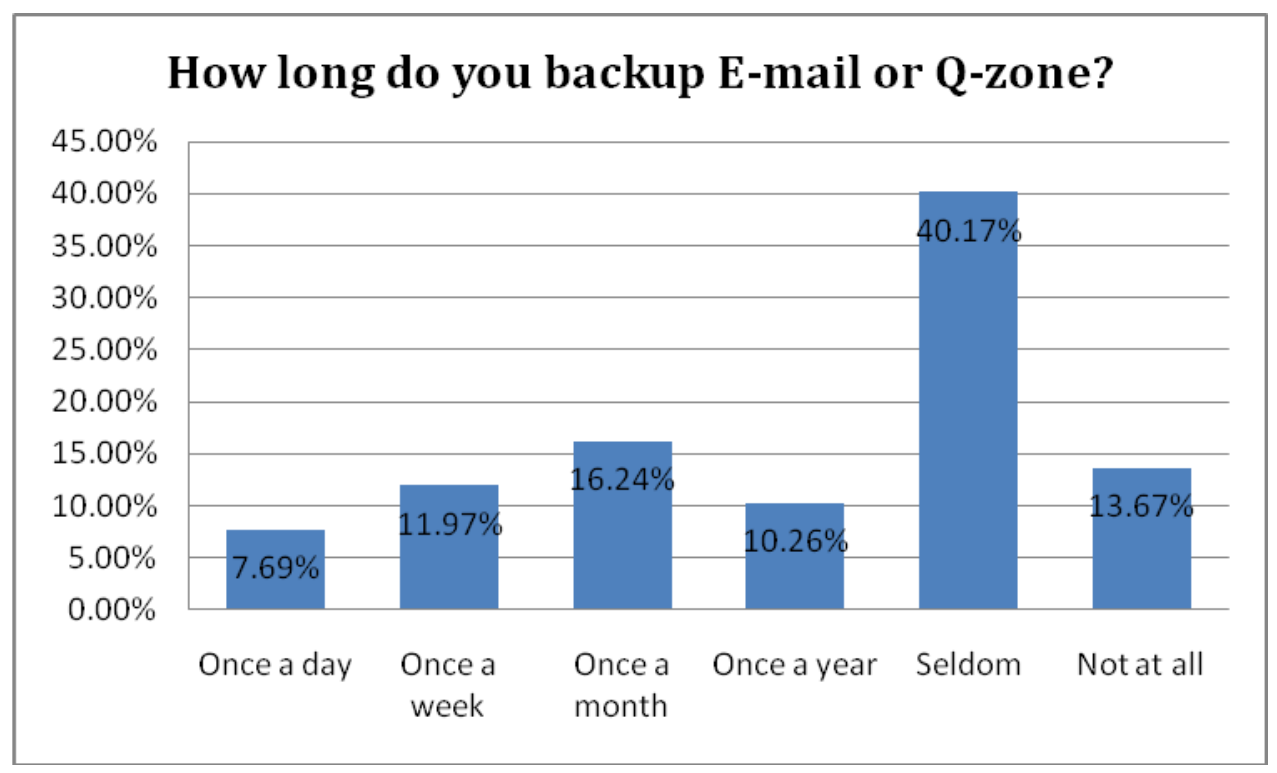

Figure 8. How long do you backup E-mail or Q-zone

The result of our study is different from Donghee Sinn et al. (2011)'s, which announced that individual had had high awareness of risk to regularly backup personal data. It indicates that the risk awareness and response of Chinese university students are relatively lagging behind in personal digital archiving, which probably relates to the duration and experiences of internet usage.

\subsection{Difficulties and Obstacles University Students Encounter}

Besides lacking of risk awareness, lagging behind of personal digital archiving also results from the obstacles and difficulties that nearly one third investigated university students encountered when they preserved personal information in E-mail or Q-zone. These obstacles and difficulties include (multi-choices): the preservation functions unavailable; preserving each file manually with "copy" and "paste"; saving information but unable to filing it; the ISP not providing any preservation function; only can print, and etc.. All of the above is resulted from ISP not developing effective network platforms.

Some university students are difficult to preserve their personal information in E-mail or Q-zone because they are lack of the knowledge of personal digital archiving. About one fourth students denoted that the most serious difficulties they encountered were not the information preservation functions whether ISP provided or not, but they did not know how to use them to save information. In addition, only $40 \%$ university students ever found other information storage tools, facilities, applications or systems to preserve their personal information. Even few students $(5 \%)$ really used other information storage tools or facilities, e.g. Outlook, Thunderbird, "Save As" function on the Internet, Furl or Google desktop, and etc. to preserve their personal information. All in all, there are two kinds of difficulties and obstacles faced to university students when they preserve their personal information in E-mail or Q-zone: one is from ISP; the other is on an individual level, that is to say, the university students are always inactive in personal digital archiving. The result of our study is coincide with Donghee Sinn et al. (2011)'s conclusion, which is having difficulties in preservation of web contents did not seem to be a sufficient driving force for further actions.

As for the important features for a good archiving tool, the university students in our research pay more attention to storage capacity $(66.67 \%)$, who hope the network platform have large storage capacity to save more personal information. On the other hand, the retrievability (the capacity of retrieving lost data) and compatibility (the capacity of keeping original format and layout of data) of the platform are also the features the students concern. However, in Donghee Sinn et al. (2011)'s investigation, the individual paid the most attention to retrievability $(17.62 \%)$, and then usability (15\%); storage capacity $(14.73 \%)$ is the next. Compared the two researches' results of our study and Donghee Sinn et al. (2011)'s, we can find that the requirement of Chinese university students to personal digital archiving in network platform is more concentrated on "save", but not "retrieve" abroad. The standpoints of both are different.

For the storage function of E-mail or Q-zone, or other preservation tools or equipments, $25 \%$ university students would love to pay 1-50 RMB per year, 5\% 50-100 RMB, 3\% more than $100 \mathrm{RMB}$. That is to say, parts of them (33\%) have a strong desire for an appropriate tool to save their data, while $67 \%$ do not. It is perhaps because: firstly, most university students have not realized the importance of personal digital archiving, and they do not want to pay for it; secondly, they think the existed free storage functions 
have met their requirements, and they do not need to pay any more.

As for how to organize or file personal information (multi choices), 55.68\% university students choose the simplest method, which is "classifying or creating folders according to different purposes"; $46.15 \%$ choose "filing information with special icons or labels provided by ISP, e.g. flag or star icons to important emails"; $29.67 \%$ choose "sorting data according to date, senders, subjects and etc."; $23.81 \%$ choose "labeling or adding keywords, metadata to each piece of information in order to describe its characteristics"; 21.98\% choose "applying for different E-mail or Q-zone accounts according to different purposes"; $29.30 \%$ choose "not organize or file personal information". It indicates that the ability of personal information management (PIM) of university students in
China remains to improve.

\subsection{Stakeholders of Personal Digital Archiving and Their Responsibilities}

Besides the investigation results of university students' awareness and behavior of personal digital archiving in E-mail or Q-zone, we also interviewed 8 information professionals to know something about the stakeholders of personal digital archiving and the responsibilities of each of them.

According to qualitative analysis of interview recording transcription from two aspects, one of which is stakeholder, the other is responsibility, we generalized three primary stakeholders, who are network users (university students in our study), information professionals and ISP. Their definite responsibilities can be summarized in table 1 .

Table 1. Stakeholders of personal digital archiving and their responsibilities

\begin{tabular}{|c|c|c|}
\hline Stak & Existing problems & Responsibilities \\
\hline $\begin{array}{l}\text { Web users } \\
\text { (university } \\
\text { students in our } \\
\text { study ) }\end{array}$ & $\begin{array}{l}\text { - Lacking of the awareness of personal digital } \\
\text { archiving (PDA) } \\
\text { Lacking of the initiatives of PDA, unwilling } \\
\text { to find or try other storage tools } \\
\text { - } \quad \text { Lacking of operational capacity of PDA } \\
\text { - Lacking of information organization } \\
\text { capacity } \\
\text { Lacking of risk awareness, and information } \\
\text { backup habit }\end{array}$ & $\begin{array}{l}\text { - } \text { Recognizing the importance of personal history in } \\
\text { E-mail and Q-zone } \\
\text { - } \quad \text { Improving the awareness and initiatives of PDA } \\
\text { Being familiar to related functions and tools of } \\
\text { PDA, and improving operational capacity and } \\
\text { information organization ability } \\
\text { Improving risk awareness, and forming good habit } \\
\text { of PDA and persisting }\end{array}$ \\
\hline $\begin{array}{l}\text { Information } \\
\text { professionals }\end{array}$ & $\begin{array}{l}\text { - } \quad \text { Lacking of PDA instruction to web users } \\
\text { Lacking of the general skills of information } \\
\text { appraisal } \\
\text { - The methods of information classification } \\
\text { and disposal are imperfect } \\
\text { Information search engines lag behind, so } \\
\text { the retrieval efficiency is low }\end{array}$ & $\begin{array}{l}\text { - Promoting PDA consciousness of web users, and } \\
\text { instructing their activities } \\
\text { - Strengthening PDA theoretical researches, e.g. } \\
\text { information appraisal, organization and retrieval } \\
\text { - Knowing about web users' general and individual } \\
\text { requirements of PDA, and transforming them into } \\
\text { system functional requirements } \\
\text { Performing web users' feedback well, and taking } \\
\text { part in system design and network platform } \\
\text { development with ISPs } \\
\text { - Solving the problems of saving E-mails repeatedly }\end{array}$ \\
\hline $\begin{array}{l}\text { Internet Service } \\
\text { Providers (ISPs) }\end{array}$ & $\begin{array}{l}\text { - Information preservation functions of } \\
\text { E-mail and Q-zone are imperfect, especially } \\
\text { the function of batching backup } \\
\text { The storage spaces of E-mail and Q-zone } \\
\text { are limited, which is influenced by personal } \\
\text { credits, web users' grades, and the payment } \\
\text { The network platform is unstable, so it } \\
\text { cannot provide lasting services } \\
\text { The retrieval function of E-mail and Q-zone } \\
\text { is imperfect, which depends on title, but not } \\
\text { content, too much } \\
\text { The safety and security of E-mail or Q-zone } \\
\text { are low } \\
\text { The functions of information arrangement, } \\
\text { classification, migration and sharing in } \\
\text { E-mail and Q-zone are imperfect }\end{array}$ & $\begin{array}{l}\text { - Reinforcing the construction of network platform, } \\
\text { providing better user experiences, reinforcing its } \\
\text { safety and security, improving retrieval } \\
\text { performance, protecting its stability } \\
\text { - Providing the functions of bulk download, } \\
\text { management and classification of social networks } \\
\text { Providing diverse network services to satisfy } \\
\text { different users' individual requirement } \\
\text { Improving information feedback function, } \\
\text { responding users' requirements timely } \\
\text { Reinforcing cooperation with information } \\
\text { professionals, following their suggestion and } \\
\text { proposal }\end{array}$ \\
\hline
\end{tabular}


The role definitions of the three stakeholders in personal digital archiving can be summarized as "requirements proposing - requirements transforming - requirements achieving". The network users generate personal information when they login onto the internet, and then they will put forward their own requirements of preserving web content. The information professionals utilize their specialized knowledge to participate in system design activities in order to transform the users' information preservation requirements to system functional requirements. ISPs provide network platforms to put the system functional requirements into reality and come into service in order to satisfy the users' requirements. The role definitions and cooperation model of each of them can be found in Figure 9.

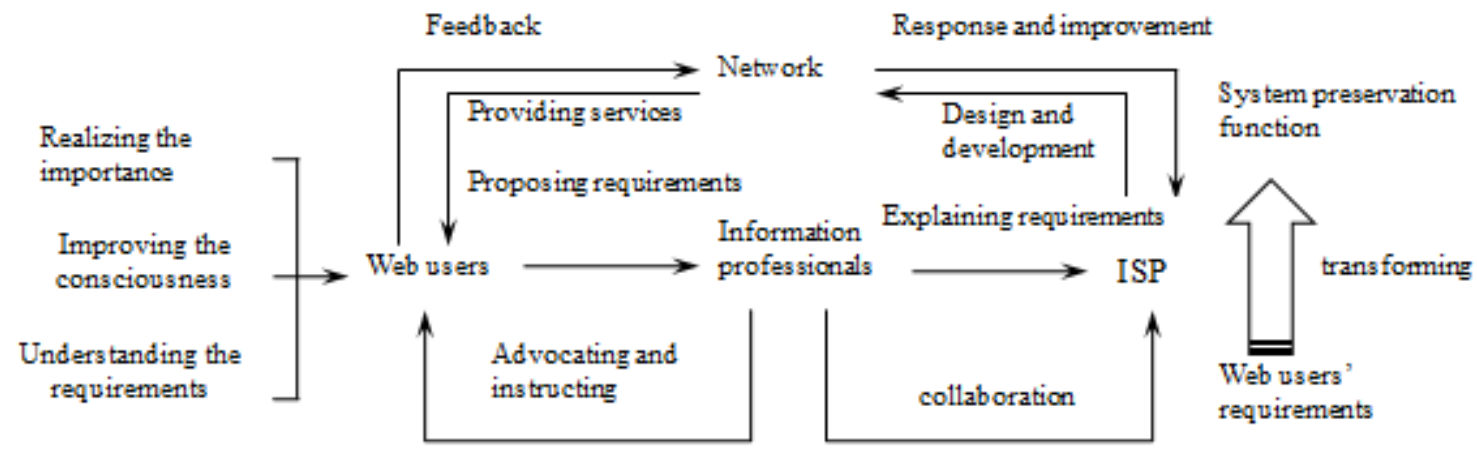

Figure 9. Stakeholders' tripartite cooperation model

In this tripartite cooperation model, we can find that the information professionals act as the "bridge" or "intermediary agent". On one hand, they need to know more about the information requirements of the web users, in particular, their personalized demands. And then they should transfer these demands into system functional requirements. On the other hand, the information professionals should also collaborate with ISP to participate in the designing and developing system functions, such as bulk downloading, managing, classifying, evaluating the social media information, and so on. As a result, the information professionals should do two things well, one of which is to reinforce the web users' information requirements research in different contexts, the other of which is to master the knowledge of system analysis and network technology, so that they can communicate with the ISPs and developers to take part in their work.

\section{Discussion}

In our research, the purposes of using E-mail and Q-zone of university students, the characteristics of personal archiving behavior, the preservation tools and their performance, the risk of personal information preservation, the personal digital archiving stakeholders and their responsibilities are discussed based on questionnaire surveys and interviews. In this section, we attempt to explain each of these findings.

Firstly, E-mail and Q-zone have become the platforms for university students to preserve their personal network information, including personal working and studying information, and personal ordinary life information, which should draw attention from the experts, and some of which should be preserved as archives.
College students are a unique population (John, 2002). In 2002, the Pew Internet and American Life Project released a major report on the use of the Internet by college students and how they have incorporated it into their education and social lifestyles (Jones, 2002). It reported the purposes for Internet use among students fell into two categories: educational and social. In college students' academic environment they reported using the Internet to contact professors, conduct research, work on collaborative projects with other students, and receive messages from academically oriented e-mail services. The results of our research verify the above conclusion further. That is to say, the main purpose of university students using E-mail is education, while using Q-zone is social purposes. It is because of with the growing recognition of email as a formal document and a legally binding form of documentation (Datskovsky \& Moerdler, 2003). Furthermore, the university students would love to regard E-mail as the tool to handle with school- or work-related things since they think E-mail is a kind of more formal and serious representation with large attachments. Meanwhile, as Q-zones gradually change to social networking services, the purposes of university students using Q-zone are more concentrated on social activities, e.g. personal communication and sharing.

In this research we found the university students have regarded E-mail and Q-zone as the places to preserve their own history which is relevant to their lives. Whether the university students could manage their personal history information well depends on their ability of personal information management, which includes the ability of acquiring, creating, storing, organizing, preserving, retrieving, utilizing and delivering information required by tasks accomplishment, the ability of performing all kinds of duties and responsibilities (Jones W, 2006), and the ability of personal digital archiving, especially the 
perception and ability of archiving provenance information. For example, if university students want to preserve his/her own E-mail A corresponding with others, he/she should also intend to preserve all other E-mails related to A to help to understand E-mail A better in the future since these related E-mails (provenance information) can rebuild the corresponding context at that time. This kind of function could also be implemented automatically in the system. That is to say, when user wants to preserve E-mail A, its related E-mails would be listed automatically by the system to ask the user if he/she wants to preserve all of these E-mails at the same time.

In addition, some university students would love to backup personal history for many copies. As a result, on one hand, the storage space would be occupied too much. On the other hand, the university students should also pay more attention to the problems of information fragmentation (Teevan et al., 2006) and multi-version when they preserve personal history. The problem of information fragmentation refers to different web content in different copies since university students forget to update all the copies. Sometimes the information about the same thing stored separately in many places can also result in this kind of problem.

Secondly, we should pay more attention to the users' information requirements, including spiritual and material needs, when we archive or appraise personal information, which is different from Functional Appraisal Theory suitable to organizational and institutional information appraisal (e.g. governments, enterprise and public institutions). In our research, we find the theory of personal information archiving and arrangement is very special. We should not only consider the particularity of personal archive compared to institutional one, but take the diversity of individual character, requirement and preference into account when we build the theory related to personal information collection, arrangement and appraisal.

Some scholars have recommended archiving all e-mail messages (Dando-Collins, 2006), but it is impossible for the limited storage spaces. We think it is necessary to draw up some specific selection criteria to decide which kind of personal digital information in E-mail or Q-zone should be preserved. Furthermore, the preservation scope should be designated based on network users' information requirements (in our study, the network users are university students). They should not only think over work- or business-related requirements, but personal spiritual reliance. They should also pay more attention to preserve personal history with the special value of E-mail and Q-zone other than other information storage places.

Thirdly, the result of our study indicates that the main obstacle university students encounter when they preserve personal information in E-mail and Q-zone is derived from internal factors (e.g. their weak consciousness, their activities lack of initiative), but not external ones. The findings of our research are different from Sinn (2011)'s, which presented technical difficulties for preservation seemed to prevent them from archiving more actively.

There are two different kinds of difficulties and obstacles that the university students encounter when they preserve their E-mail and Q-zone. One of them is the ISP functional defection which is the external factors. It means ISP has not developed a well-functioned network platform. For example, nearly one-third university students met unusable preservation function, so they can only COPY and PASTE their personal information manually. Sometimes the information can only be saved, but cannot be archived; sometimes ISP has not provided any preservation function except for PRINT, and so on. Another difficulty or obstacle is that the university students are lack of the knowledge of personal digital archiving which is the internal factor. On one hand, nearly one-fourth university students told us that the most serious problem they encountered is not ISP functional defection, but they did not know how to use the preservation function at all. On the other hand, most university students in our investigation regarded personal digital archiving as information storage or preservation, a kind of static activity. However, in fact there are four main characteristics and purposes of personal digital archiving, which are a series of complicated activities, e.g. digital management/curation, distributed storage, long-term preservation, and value accumulation. As a result, most university students pay more attention to the storage capacity and ability (66.67\%) when they choose the archiving tools. They would not love to pay for more archiving functions $(67.00 \%)$. As for the methods of organizing or arranging archived information, most university students tend to choose the simplest methods. For example, they would love to create different folders according to different purposes (55.68\%), differentiate important information by using some special icons or tags provided by ISP $(46.15 \%)$. As we know, it is not the real personal digital archiving.

The result of our study indicates that the main obstacle university students encounter when they preserve personal information in E-mail and Q-zone is derived from internal factors (e.g. their weak consciousness, their activities lack of initiative). It is because university students have not realized the important value of the information, just as most university students would not love to pay for the information preservation functions in E-mail, Q-zone or other tools and equipment. The Digital Lives Project also found that only a small number of survey participants answered a computer file created or acquired from e-mail and blogs was of great importance to them in their personal or working life. (John et al.,2010). However, it would be a big mistake to regard the information in E-mail and Q-zone as no value. Otherwise, the investigated university students would not feel miserable when they lost this kind of web content. In fact, it is the convenience of the internet that misleads university students to believe any kind of information is extremely easy to obtain on the web. The characteristic of convenience makes university students 
neglect the importance and unique of personal digital information, which cannot be found in the future if university students did not save it nowadays.

As a complementation, our investigation shows that it is not easy to change the behavioral habit of university students lack of initiative, so more external forces would be needed to develop their good habit of preserving personal information. The external forces refer to long-term collaboration of web users (university students in our study), information professionals and ISP. The reason is although $71 \%$ university students acknowledged they had lost their personal information and felt sad, the difficult experience is not enough to arouse the university students' consciousness to back up their information and to take actions. In order to solve this problem, strengthening the external forces is crucial.

Fourthly, although the tripartite cooperation model was proposed in our research, the information professionals need to undertake the main responsibilities of personal digital archiving, including improving users consciousness of personal digital archiving, building PDA theory, communicating users' requirements with ISP, and so on, because by now the university students' consciousness and behavior of personal archiving lag behind, while ISP emphasize more on technology development.

Another new finding of our study is that the stakeholder of personal digital archiving is not information professional (Sinn, 2011), but tripartite cooperation of web users, information professionals and ISPs, who will undertake the responsibilities of information preservation together. Within the cooperation, information professionals should serve as key roles of "medium" and "bridge". On one hand, they need to know about the information preservation requirements of web users, especially their individual needs, and then transform the users' requirements into system's functional requirements. On the other hand, information professionals should also collaborate with ISPs to design and develop functions of network platform (e.g. downloading, managing and classifying bulk of information in SNS, identifying the value of web content). In order to qualify the key role, they must finish two kinds of things well, one of which is to strengthen research of different web users' requirements in different context, the other of which is to master system analysis knowledge, know something about network techniques, communicate with ISPs and system developers and take part in their work.

One of the information professionals in our interviews presented, "since the personal information management activities are different from each other, the requirements and habits of individuals are also different, information professionals could not provide specific support and help to each person." Of course, there are a lot of influence factors in personal information management, which include format or type of information (Tungare, 2007; Teevan et al. 2006), individual's intended use of information
(Hardof-Jaffe et al., 2009; Bruce et al. 2004), PIM tools and applications (Bergman et al., 2007), skills and abilities of the individual (Bruce et al., 2004), size of collection (Elsweiler et al., 2007), time (Boardman and Sasse, 2004), individual differences/attitudes/habits (Chang and Ko, 2008; Henderson, 2009), and memory (Elsweiler et al., 2007), among others. The influence factors in personal information management among university students include format, PIM skills and abilities, size of collections, individual habits, and memory capabilities (Otopah et al., 2013). Although these influence factors make personal information management activities diverse and personalized, it does not hinder information professionals to raise web users' awareness of personal digital archiving, to urge web users to form good habits. As for making a specific persona digital archiving scheme for someone, or certain group, web users should finish it by themselves with the help of information professionals.

As the web users, university students cannot fulfill personal digital archiving tasks overnight. It is integral to the learning process (Bergman et al., 2007) and students should regularly perform it. In the whole archiving process, the responsibilities of university students are both explaining clearly their own information preservation requirements which is the key step, and acting on their own initiative; both planning suitable information preservation programs with the help of information professionals, and developing good habits of their own.

Furthermore, ISPs also should take the responsibilities of personal digital archiving. However, it is risky to depend on them only. As a result, ISPs should collaborate with information professionals to know about web users' requirements of all kinds, according to which, they could develop relevant system functions to provide internet services. At the same time, ISPs need to improve information feedback functions of the network platform in order to provide better web users' experiences through adopting web users' suggestions and response in time.

\section{Conclusions}

A major report of the Pew Internet and American Life Project found that as a group, college students are early adopters of the Internet incorporating new uses of its features before other population groups (Jones, 2002). The university students are the largest group in cyber citizens and their activeness is higher. So it is meaningful to study university students' personal digital archiving activities. However, there are also some limitations and prospects of this research. (1) The discipline backgrounds of the university students in our research did not distribute evenly, among which the students from the science of management and economy are $60 \%$, while the students in other majors are less. It may influence the research results. However, we will do better in our future research. In addition, we only 
investigated the information behavior when the university students preserved E-mail and Q-zone, while other information preservation behavior has not been considered. All the above would be studied further. (2) The influence factors of personal digital archiving proposed in our research are concluded from qualitative study, but not quantitative study. In the future, we will measure the degree, mechanism the influence factors impacting to personal digital archiving, and the relationship between these factors. (3) The information professionals proposed in our research is a group, which includes librarians, archivists, professors and students major in information science, and people working in information-related institutions. However, the responsibilities of information professionals defined in this research are based on the group, but not any sub-group or individual. The sub-groups' or individual responsibilities will be studied in future research.

\section{REFERENCES}

[1] Bagozzi R P, Ue H M, VanLoo M E (2001). Decisions to donate bone marrow: The role of attitudes and subjective norms across cultures, Psychology and Health, 16, 29-56.

[2] Bergman, O., Beyth-Marom, R. and Nachmias, R. (2007), The user-subjective approach to personal information management systems design: evidence and implementations, The American Society for Information Science and Technology, 59(2), 235-246.

[3] Boardman, R., \& Sasse, M. A. (2004). Stuff goes into the computer and doesn't come out: A cross-tool study of personal information management. In E. Dykstra-Erickson, \& M. Tscheligi (Eds.), Proceedings of the SIGCHI Conference on Human Factors in Computing Systems, Vienna, Austria, 583-590. New York, NY: ACM.

[4] Boardman, R., Sasse, M. A., Spence, B. (2002).Life beyond the mailbox: A cross-tool perspective on personal information management.. Paper presented at the CSCW 2002 Workshop: Redesigning Email for the 21st Century, New Orleans, LA.

[5] Bruce, H., Jones, W. \& Dumais, S. (2004). Information behaviour that keeps found things found. Information Research, 10(1), paper 207 [Available at http://InformationR.net/ir/10-1/paper207.html] (accessed 2014-8-24).

[6] Burrows, T. (2006), Personal electronic archives: collecting the digital me, OCLC Systems and Services, 22(2), 85-88.

[7] Chang, S.J. and Ko, M.H. (2008), Behaviors of PIM in context of thesis and dissertation research, CHI 2008 Workshop, Florence, Italy, ACM Press, New York, NY.

[8] Cox, R. J. (2009).Personal archives and a new archival calling: Readings, reflections and ruminations. Duluth, $\mathrm{MN}$ : LitWin Books.

[9] Cushing, A. L. (2010). Highlighting the archives perspective in the personal digital archiving discussion. Library Hi Tech, 28, 301-312.

[10] Dando-Collins, S. (2006). The e-mail, the whole e-mail, and nothing but the e-mail. Records Management Society Bulletin, 132, 5.

[11] Datskovsky, G., Moerdler, M. (2003). Solving the e-mail challenge: Effectively managing e-mails as documents of record. Record Management Society Bulletin, 113, 5-9.

[12] Donghee Sinn, Sue Yeon Syn, Sung-Min Kim (2011). Personal records on the web: Who's in charge of archiving, Hotmail or archivists?. Library \& Information Science Research, 33, 320-330.

[13] Elsweiler, D., Ruthven, I. and Jones, C. (2007), Towards memory supporting personal information management tools, Journal of The American Society For Information Science And Technology, 58(7), 924-946.

[14] Gross, B. M. (2004). Multiple email addresses: A socio-technical investigation. Paper presented at the First Conference on Email and Anti-Spam (CEAS), Mountain View, CA. July 30-31, Retrieved from http://ceas.cc/2004/183.pdf.

[15] Hardof-Jaffe, S., Hershkovitz, A., Abu-Kishk, H., Bergman, O. Nachmias, R. (2009), Students' organization strategy of personal information space, Journal of Digital Information, 10(5), 1-17.

[16] Henderson, S. (2009), Guidelines for the design of personal document management user interfaces, Personal Information Management: PIM 2009 ASIS\&T 2009 Workshop, Vancouver, Canada.

[17] Hobbs, C. (2001). The character of personal archives: Reflections on the value of records of individuals. Archivaria, 1(52), 126-135.

[18] Horrigan, J. B., Rainie, L. (2002). Emails that matter: Changing patterns of Internet use over a year's time. IT \& Society, 1(1), 135-150.

[19] Marshall, C. C. (2008a). Rethinking personal digital archiving, Part 1: Four challenges from the field. D-Lib Magazine, 14(3/4). Retrieved from

http://www.dlib.org/dlib/march08/marshall/03marshall-pt1 .html.

[20] Marshall, C. C. (2008b). Rethinking personal digital archiving, Part 2: Implications for services, applications, and institutions. D-Lib Magazine, 14(3/4). Retrieved from http://www.dlib.org/dlib/march08/marshall/03marshall-pt2 .html.

[21] Marshall, C. C., Bly, S., \& Brun-Cottan, F. (2006). The long term fate of our personal digital belongings: Toward a service model for personal archives. In S. Chapman, \& S. A. Stovall (Eds.), Archiving 2006: Final program and proceedings, Ottawa, Canada, pp. 25-30. Springfield, VA: Society for Imaging Science and Technology.

[22] John, J. L., Rowlands, I., Williams, P., \& Dean, K. (2010). Digital lives: Personal digital archives for the 21 st century, an initial synthesis. (Digital Lives research paper). Retrieved from http://britishlibrary.typepad.co.uk/files/digi tal-lives-synthesis02-1.pdf.

[23] Jones, S. (2002). The Internet goes to college: How students 
are living in the future with today's technology. Pew Internet \& American Life Project. Retrieved from http://www.pewInternet.org/reports.

[24] Jones, W. (2006). Personal information management. The Annual Review of Information Science and Technology, 41(1), 453-503.

[25] William Jones, Manuel Perez-Quinones. Towards a field of PIM inquiry. 2005-01-27,http://pim.ischool.washington.edu/1.\%20towar ds\%20a\%20field\%20of\%20PIM\%20inquiry,\%20report, \% 20final.pdf, 2017-03-23.

[26] Lansdale, M. (1988). The psychology of personal information management. Applied Ergonomics, 19(1), 5566.

[27] O'Reilly, T. (2005), What is Web 2.0? Design patterns and business models for the next generation of software, online, available at: www.oreillynet.com/pub/a/oreilly/tim/news/2005/09/30/w hat-is-web-20.html.

[28] Otopah, F.O., Dadzie, Perpetua (2013), Personal information management practices of students and its implications for library services, Aslib Proceedings: New Information Perspectives, 65(2), 143-160.

[29] Perry, C. (2008). Mind your messaging: Risks, inefficiencies increasingly spark need for effective messaging control. Processor, 30(4), 1. Retrieved fromhttp://www.processor.com/editorial/article.asp?article $=$ articles $\% 2 F p 3004 \% 2 F 20$ p04\%2F20p04.asp.

[30] Teevan, J., Jones, W., Bederson, B. B. (2006), Personal information management, Communications of the ACM, 49(1), 40-43.

[31] Tungare, M. (2007), Understanding the evolution of users' personal information management practices, Proceedings of the Eleventh IFIP TC13 International Conference on Human-Computer Interaction-INTERACT 2007 Doctoral Consortium.

[32] Waters, D. (2005). Managing digital assets: An overview of strategic issues. Paper presented at CLIR Workshop: Managing Digital Assets: a Primer for Library and Information Technology Administrators, Charleston, SC. Washington DC: Council on Library and Information Resources. Retrieved from http://www.clir.org/activities/registration/feb05 spkrnotes/ waters.htm.

[33] Whittaker, S., Sidner, C. (1996). Email overload: Exploring personal information management of email. In R. Bilger, S. Guest, \& M. J. Tauber (Eds.), Proceeding of Conference on Human Factors in Computing Systems (CHI 96), Vancouver, BC, Canada, 276-283. New York, NY: ACM.

[34] Williams, P., Dean, K., Rowlands, I. \& John, J.L. (2008). Digital lives: Report of interviews with the creators of personal digital collections. 55. Retrieved from http://www.ariadne.ac.uk/issue55/williams-et-al/. 